\title{
Alles verändert sich und alles bleibt gleich
}

\section{Matthias Scholer}

Chefredaktor SÄZ

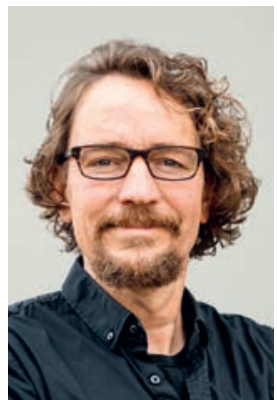

«Welche Veränderungen wird es nun bei der SÄZ geben?», werde ich standardmässig gefragt, wenn ich mich als neuer Chefredaktor vorstelle. Die Frage mag immer dieselbe sein, aber die Tonalität, mit der sie gestellt wird, unterscheidet sich je nach dem Gegenüber. Da sind einerseits diejenigen, die das nun erwartungsvoll, ja schon fast ungeduldig betonen - so als warteten sie schon längst auf einen Sturm im Blätterwald. Andererseits gibt es die eher konservativen Leser, bei denen das Wort Veränderungen mit einem Vibrato unterlegt wird, welches vermuten lässt, dass sie windstille Zeiten bevorzugen.

Tatsächlich sind einige Änderungen rund um die SÄZ unabdingbar. Nachdem die Delegiertenversammlung beschlossen hatte, die Sockelbeiträge zu Gunsten der Schweizerischen Ärztezeitung und des Swiss Medical Forum (SMF) per Anfang 2019 zu streichen, erhalten die FMH-Mitglieder beide Zeitschriften seit bald einem Jahr kostenlos. Seitens des Schweizerischen Ärzteverlags EMH müssen wir folglich neue Wege finden, um diese finanzielle Einbusse zu kompensieren.

Auf der Einnahmeseite gibt es kurzfristig nicht viele Alternativen: Es gilt, den Anzeigemarkt auszubauen. Im Print und Online. Dies ist jedoch einfacher geschrieben, als gemacht. Schliesslich kämpfen die Printmedien generell mit einem abnehmenden Anzeigenmarkt. Doch wir sind überzeugt, diesem Trend dank neuen Inhaltskonzepten und Produkten erfolgreich entgegenwirken zu können und damit den Umsatz nicht nur halten, sondern steigern zu können.

Auf der Ausgabenseite haben wir schon einige griffige Massnahmen in die Wege geleitet: So wird die SÄZ nicht mehr in Muttenz, sondern bei der Vogt-Schild Druck AG mit Sitz im solothurnischen Derendingen gedruckt. Das Unternehmen bietet das für den Druck der SÄZ am besten geeignete Verfahren, was sich in merklich tieferen Produktionskosten niederschlägt. Aber auch in der Produktionsphase, während der aus einer Worddatei ein fertig gestalteter Artikel entsteht, wird es im Laufe des kommenden Jahres zu tiefgreifenden Veränderungen kommen. Dank der Software «Xpublisher» werden künftig eingereichte Texte schnell, standardisiert und grösstenteils automatisiert verarbeitet. Was ändert sich dadurch für unsere Autorinnen und Autoren? Ähnlich zu Einreichungsplattformen im Bereich der Wissenschaftspublikationen laden die Autoren ihre Beiträge künftig über ein Online-Formular hoch. Nach der Begutachtung durch die Redaktionskommission wird der Artikel lektoriert und automatisch grob gelayoutet. Danach haben die Autoren die Möglichkeit, ihren Beitrag online einzusehen und letzte Wünsche anzugeben, bevor der gestalterische Feinschliff durch die Typographen erfolgt. Im Zuge dieser Umstellung werden wir auch unsere Autorenrichtlinien schrittweise anpassen müssen. Sie finden die jeweils aktuelle Version auf der SÄZ-Website unter dem Menüpunkt «Publizieren».

Nun habe ich einiges über bevorstehende Veränderungen berichtet. Doch es gibt auch viele bewährte Elemente, die unangetastet bleiben. So wird beispielsweise am dualen Aufbau, den mein Vorgänger Bruno Kesseli etablierte, nicht gerüttelt: Vorne erscheinen die offiziellen Stellungnahmen der FMH und verschiedener Organisationen.

Der hintere Teil ist journalistisch völlig frei und bietet Einzelautoren wie auch Autorengruppen ein Forum. Damit bleibt die SÄZ eine Informations- und Diskussionsplattform mit breiter Meinungs- und Themenvielfalt.

Was wäre also die beste Antwort auf die eingangs erwähnte Frage bezüglich der Zukunft der SÄZ? Ich denke, eine Strophe aus einem Lied der deutschen Band Silbermond eignet sich gut als Antwort: "Alles verändert sich und alles bleibt gleich.» Oder etwas weniger poetisch ausgedrückt: Anpassungen an die neuen Rahmenbedingungen sind notwendig, das Bewährte wird erhalten und gepflegt.

Zum Schluss gebe ich Ihnen noch ein Rätsel für die bevorstehenden Feiertage auf: Nächstes Jahr gibt es einen guten Grund zum Feiern. Was könnte der Anlass dafür sein? Keine Ahnung? Ich helfe Ihnen ein bisschen: Auf jeder Seite dieser Ausgabe ist ein sachdienlicher Hinweis versteckt.

Ich wünsche Ihnen, liebe Leserinnen und Leser, viel Spass beim Raten, eine besinnliche Weihnachtszeit und einen optimalen Start ins 2020! 